Portland State University

PDXScholar

1979

\title{
An experimental model using dance training as therapy for women over thirty five
}

Thelma J. Lofquist

Portland State University

Follow this and additional works at: https://pdxscholar.library.pdx.edu/open_access_etds

Part of the Dance Commons, and the Psychology Commons

Let us know how access to this document benefits you.

\section{Recommended Citation}

Lofquist, Thelma J., "An experimental model using dance training as therapy for women over thirty five" (1979). Dissertations and Theses. Paper 2793.

https://doi.org/10.15760/etd.2787

This Thesis is brought to you for free and open access. It has been accepted for inclusion in Dissertations and Theses by an authorized administrator of PDXScholar. Please contact us if we can make this document more accessible: pdxscholar@pdx.edu. 
AN ABSTRACT OF THE THESIS OF Thelma J. Lofquist for the Master of Arts in Psychology presented July 16, 1979.

Title: An Experimental Model Using Dance Training as Therapy for Women Over Thirty Five.

APPROVED BY MEMBERS OF THE THESIS COMMITTEE:
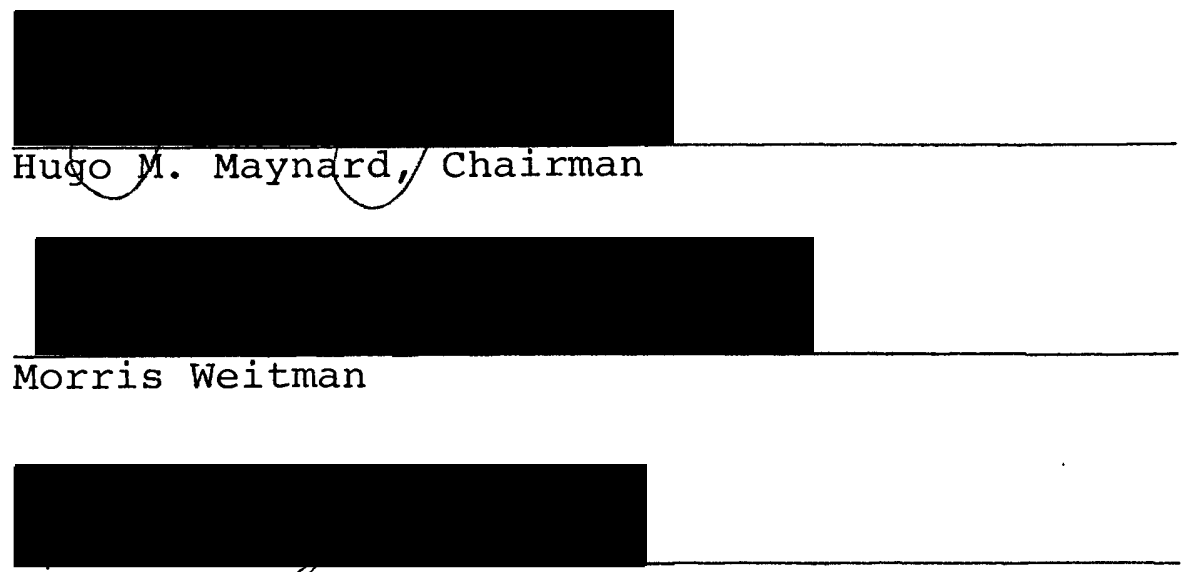

Barbara Stgurt

The intent of this study was to use an experimental model to investigate the use of dance training for improving the self-esteem of women over the age of 35 .

Sixteen women over the age of 35 were taught jazz dance over a 10 week period. A pre and post test of the Tennessee Self Concept Scale was used on both a dance group and a no dance group. It was hypothesized there would be positive changes in three of the 10 scores in the TSCS for the dance group, but not for the no dance group. The scores predicted to were Physical Self, Personal Self, Self Satisfaction. 
Analysis of covariance confirmed change in the Physical and Personal scores for the dance group but no change in the self Satisfaction score. Behavioral self and Total $\mathrm{P}$ scores also changed for the dance group 
AN EXPERIMENTAL MODEL USING DANCE TRAINING AS THERAPY FOR WOMEN OVER THIRTY FIVE

by

THELMA J. LOFQUIST

A thesis submitted in partial fulfillment of the requirements for the degree of

\author{
MASTER OF ARTS \\ in \\ PSYCHOLOGY
}

Portland State University

1979 
TO THE OFFICE OF GRADUATE STUDIES AND RESEARCH:

The members of the committee approve the thesis of Thelma Lofquist presented July 16, 1979.

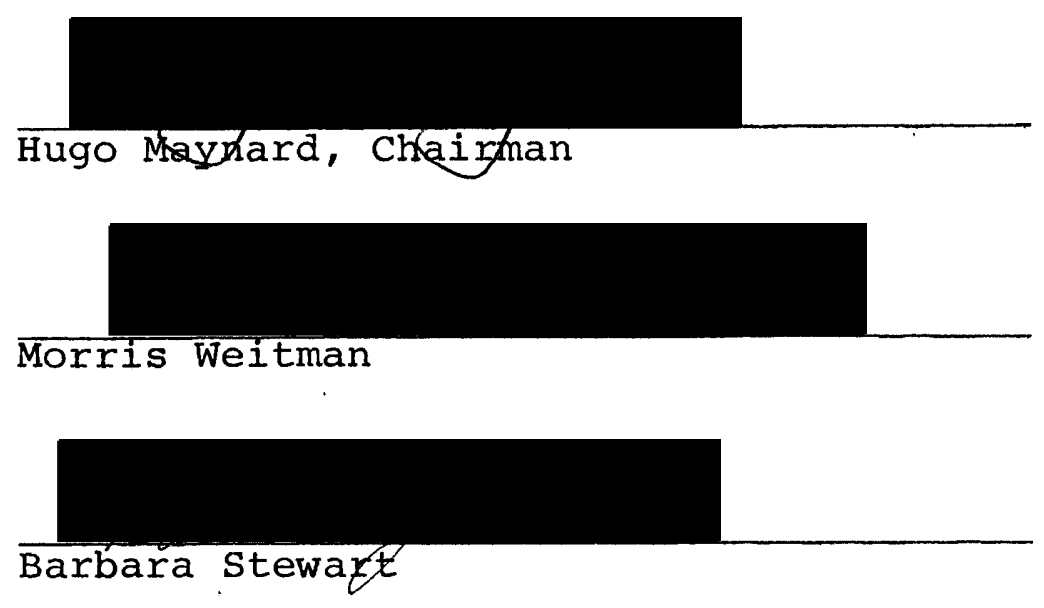

APPROVED :

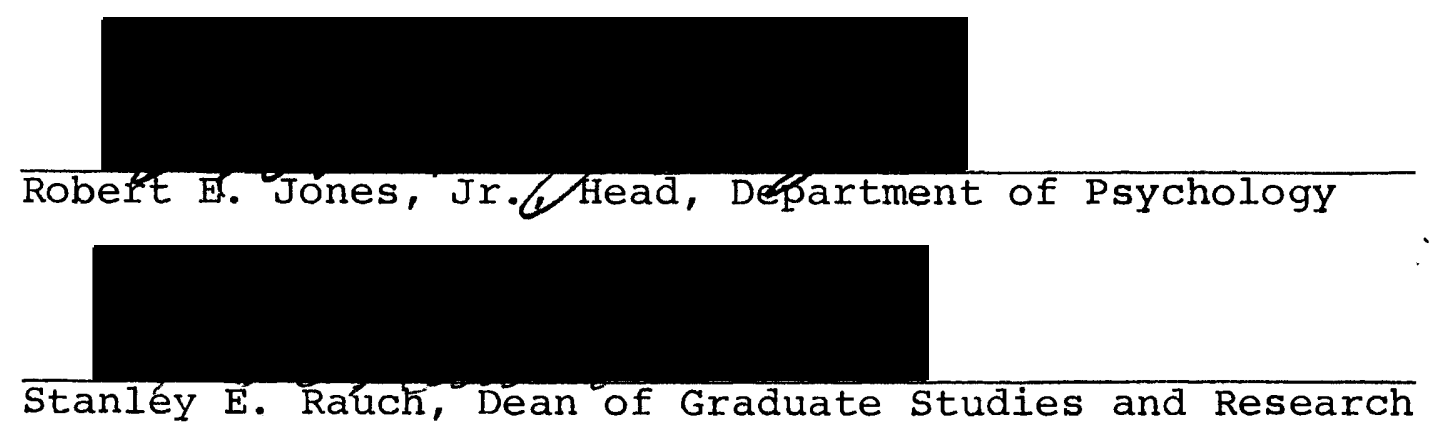




\section{ACKNOWLEDGEMENTS}

I wish to express sincere appreciation to the members of my thesis committee for their support and patience throughout this study, and to the subjects who participated in making this project possible. 
CHAPTER

I INTRODUCTION • • • • . . . . . . . . . 1

II REVIEW OF THE IITERATURE . • • • • • . . 3

Hospitalized Psychiatric Patients. • 3 Autistic Children . . . . . . . 4

Handicapped . . . . . . . . . . . 4

Dance in Education . . . . . . . 5

Overview . . . . . . . . . . . 5

III DESCRIPTION OF THE PRESENT STUDY • • • • • 7

IV METHODS • • • • . . . . . . . . . . 11

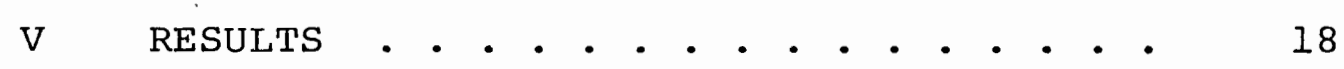

VI DISCUSSION • • • • • . • • • • • • . 20



APPENDIX • • • • • • • • • • • • • • • • • • 35 


\section{LIST OF TABLES}

TABLE

PAGE

I Means and Standard Deviations . . . . . . . 28

I Summary of Analysis of Covariance of the Ten

TSCS Scales in Comparing the Dance and

No Dance Groups . . . . . . . . . . 30 


\section{LIST OF FIGURES}

FIGURE

PAGE

1. Interaction for Physical Self Score . . . . . . 34 


\section{INTRODUCTION}

The purpose of this study is to use an experimental model to investigate the use of dance training as a tool for improving the self-esteem of women over the age of 35 .

The relationship between physical fitness and mental fitness has already been shown in earlier research (Garvin, 1972; Salkin, 1973). With improved physical fitness, selfevaluation may improve (Gary, 1972) and mental performance during stress may be higher (Weingarten, 1973). Positive changes in body image may also go along with positive changes in physical abilities (McCarthy, 1973). Snygg and Combs (1959) state it clearly:
For most people the smooth running body in good condition is likely to give a feeling of enhancement of the self as being adequate, competent and in control of situations. ( $p .77)$.

Dance training not only offers physical improvement, but also teaches a new skill and provides creative outlets. Body movements become more fluid as the long, strong muscles are developed. In addition, individuals learn to use their bodies as creative instruments, innovating new movements in concert with the music; the music often. encourages more energetic body movements. For many people, dance training may provide more incentive for beginning a physical improvement program than calisthenics, swimming, 
or jogging.

The use of dance as a therapeutic tool is a fairly recent concept, but as described in the next chapter, is already being used extensively. 
REVIEW OF THE LITERATURE

Dance therapy research has been used both in and outside of institutionalized settings with diverse groups and ages. Hospitalized psychotic patients, outpatients, handicapped children, indigent children are some examples of the variation in subject populations along with many different dance techniques.

\section{Hospitalized Psychiatric Patients}

Dance was considered effective in group therapy programs for hospitalized psychiatric patients at Yale University Psychiatric Hospital by helping patients to clarify values and goals (Sandel, 1975). SHALL WE DANCE, a book by Earleen Bailles (1972), suggests that dancing helped hospitalized mental patients to learn "socially acceptable behavior" which then was transformed into "verbal communications." Music and dance have been suggested by others as therapy for mental patients who cannot communicate with words. (Shaskean, 1972; Levy, 1974). Rhythm and movement have also been considered as investigative ọ diagnostic tools in the study of behavior of psychiatric patients (Benders \& Nijmegan, 1969; Dulicai, 1973).

In other studies, dance was used to improve body images of psychotic patients (McCarthy, 1973); to benefit 
schizophrenics (Blankenberg and Frieburg, 1969; Schoop \& Mitchell, 1974); to help patients who had problems with body and ego identities (Salkin, 1973); and to deal with problems of depression and hostility (Lefco, 1974).

\section{Autistic Children}

Elaine Seigal (1973) has done dance therapy with autistic children, and reported some progress using rhythmic exercises and dancing, coupled with body contact and verbal and non-verbal interpretations. While some of her methods have been criticized on the grounds that she was unable to systematize listening, looking, touching and talking, and at the same time doing exercises and dancing (Kestenberg, 1973) and that her teaching may have been a function of her individual sensitivities (Solnit, 1974), the value of the dance therapy itself was not questioned. In another study of autistic children, coupling movement education with swimming sessions, the subjects were shown to have clearly improved their motor skills (Best \& Jones, 1975).

\section{Handicapped}

Norma Canner (1968) demonstrated, by using photographs, that creative movement and dance stimulate physical and emotional growth of mentally handicapped children. Teacher workshops have used her teaching methods to isolate body parts and locomotor movements. 
Hecox, Levine and Scott (1975) found noticeable physical improvement among physically handicapped adults with whom they conducted dance sessions over a three-year period. The results, however, were based entirely on self-report case histories.

Kaveler (1974) also found individual improvements as a result of using dance therapy with retarded children, but noted that it was difficult to demonstrate this experimentally.

Dance in Education of Children

Dance has been used in a program for migrant children to help them escape from their normal roles (Seriale, 1976); to facilitate non-verbal expression and problem solving in children (Glen Haven Achievement Center); to help deal with learning disorders (Frank, 1975); to increase self-esteem of indigent children (Golin, 1969); as lessons in movement vocabulary, group relationships and spatial patterning (Docherty, 1975); and to help self-understanding in disadvantaged youth (Reed, 1970).

\section{Overview}

Dance has been used in day care programs for psychotic patients (Gunning and Holmes, 1973; Kalmens, 1970) and in group therapy (Dilthey, 1971; Alperson, 1974). The list of studies of dance used as therapy is endless, but search of the literature reveals an emphasis on case histories as 
a means of evaluation, indicating a need for finding ways to put dance therapy in an experimental model. 


\section{DESCRIPTION OF THE PRESENT STUDY}

At the time. of this study there was no research relating dance training to levels of self-esteem. Ruth Wylie (1974) speaks to the nebulous measurements of body image tests and feelings about the self. She is critical of the construct validity of the Tennessee Self Concept Scale used in this study, but she is critical of most self concept tests and suggests methodological work on self concept should be abandoned (p. 331, 1974). She does note that

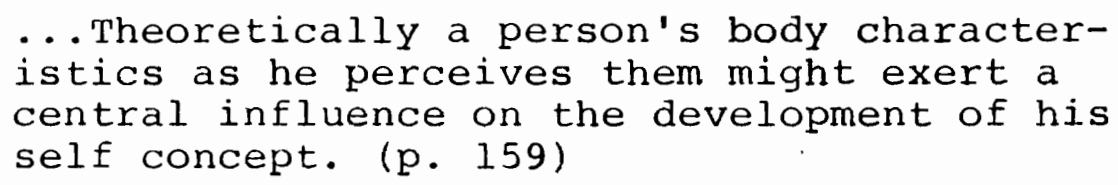

The hypothesis of this study was that there would be significant change in the measures of the Tennessee Self Concept Scale ('TSCS) of physical self, personal self, and self satisfaction for a group of women over the age of 35 , who voluntarily participated regularly in dance training classes for a period of 10 weeks.

In the TSCS there are nine dimensions or-scales used as measures of self concept with nine scores representing these dimensions and a tenth score representing the grand total of the other nine dimensions or the Total Positive Score (Total P.). 
The scales are labeled:

1. Identity

2. Self Satisfaction

3. Behavior

4. Physical Self

5. Moral-Ethical Self

6. Personal Self

7. Family Self

8. Social Self

9. Self Criticism

10. Total Positive Score

It was predicted that dance training would affect:

1. Physical Self

2. Personal Self

3. Self Satisfaction

The Physical Self scale presehts "her view of her body, her state of health, her physical appearance, skills and sexuality" (Fitts, 1965). Participants in dance training classes who systematically practice the prescribed exercises, could expect some advances in dance skill and some gains in muscle tone. These possible improvements might enhance the participants views of their "state of health, physical appearance, and skills."

The Personal Self scale reflects the individual's "personal worth and feelings of adlequacy as a person" (Fitts, 1965). If the individual perseveres in a dance training program and realizes physical improvement, it would seem that feelings of personal worth and adequacy would improve.

The Self Satisfaction score comes from the items "where the individual described how she feels about the 
self she perceives" (Fitts, 1965). Finding physical improvements from perseverance in dance training should improve self perception and self satisfaction. These three dimensions are interrelated and seemed the most likely of the 10 scores to show significant score increases.

Snygg \& Combs (1959) say that the concepts people hold about themselves will determine how they think and how they behave.

"If a man believes he is Napoleon, he will
act like Napoleon or, at least like his
concept of Napoleon." (p. 122, 1959)

So it is possible that if a woman in the middle years conceives of herself as a dancer she will think and behave like a dancer. Coombs (1962) was a personality theorist who wrote of individual behavior from a perceptual point of view. He states that a change in the perceived self is dependent upon:

1. The place of the new concept in the individual's present self organization.

2. The relation of the new concept to the person's basic need.

3. The clarity of the experience of the new perception. (p. 163)

Inasmuch as the women who participated in the present study were volunteers, it was assumed that: .

1. The new concept of themselves as dancers was within the realm of their "present self organization" because they volunteered to take dance training. 2. Women over 35, who volunteer for dance classes may be experiencing 
a lessening of physical abilities and feel a need to do something to counteract their loss of physical abilities, relating the concept of themselves as a dancer to a need for physical improvement. 3. The encouragement to do the necessary movements consistently would lead to visible physical improvement that normally occurs with consistent exercise. This would aid in the clarification of the self as a dancer.

The dance trainer in this study is the researcher. The training methods were devised when the researcher was participating in university dance classes. The difficulties experienced by a person over 35 participating in college dance classes prompted the researcher to consider special methods of teaching dance to women who were past the usual age of college freshmen. The researcher gained personal rewards from her own dance training and, after teaching dance in a mental hospital, doing dance therapy with schizophrenic patients and out-patient groups, arrived at the hypothesis of relating dance training to feelings about the self. 


\section{CHAPTER IV}

\section{METHODS}

\section{Subjects}

Thirty women over 35 years of age volunteered for jazz dance classes. They had been recruited via posters that had been placed in "singles centers", churches and laundromats (Appendix A). The posters offered free dance classes to women over 35 who had had no previous dance training. Interested persons were asked to phone the researcher. The original intent was to divide the women into two groups by randomly assigning every other volunteer to a "dance group" or a "no dance group," but some women registered with friends and did not want to be separated. As a result, the women who registered simply were alternately assigned to one of the two groups. Those who registered with friends were assigned together, and then the next person to register was put in the alternate group. The "dance" group was asked to take a self esteem test at the beginning of the 10-week session and again at the end of the 10 weeks. Those assigned to the non-dance group were told, at the time they first phoned, that the class was full; but if they took a self esteem test at that time and again before the beginning of a second class they could take the second 10-week dance course at that later time. Each member of the no-dance group was 
telephoned once during the first 10 weeks to remind her that the classes would still be offered. This contact helped insure their continued availability as a control group for the study and also added the factor of a further contact with the control group during the time of the study. Sixteen women were in the dance group, but only ten of them recorded their ages on the self esteem test. of those ten, the mean age was 44.6. In the no-dance group, twelve of the fourteen members gave their ages, and here the mean age was 46.33. Use of the $t$ test showed no significant difference $(t=.35)$.

\section{Instrument}

The TSCS was constructed as an instrument to be used in mental health research. Four procedures were used to determine the validity of the scale:

1. Content

2. Discriminations between groups

3. Correlation with other personality measures

4. Personality change under certain conditions

Buros (1970) states that several scores from the scale "have remarkably high correlations with other measures of personality functioning." The Taylor Anxiety Scale correlates -.70 with Total Positive. Correlations from . 50 to . 70 are common with the Cornell Medical Index. (Buros, 1970).

Using 188 admissions to an inpatient treatment program the TSCS Total $\mathrm{P}$ was significantly correlated with similar constructs on the High School Personality Questionnaire, 
16 Personality Factor Questionnaire, Motivation Analysis

Test and the Evaluative Factor on a semantic differential. Total $\mathrm{P}$ was also related to overall academic achievement on the California Achievement Test and the Success/Failure Inventory, and negatively related to the number of problems reported on the Mooney Problem Check List (Deiker and Lanthier 1975).

One problem mentioned by Buros (1970) is that no factor analysis has been reported to find intercorrelations among the scores in the TSCS. However, one factor analysis study used product-moment correlations among the 100 scale items and 20 interpretable factors were extracted with four measures of self: physical, moral-ethical, family, and social, lending some support to the validity of the test (Vacchiano and Strauss, 1968). A more recent factor analysis (Gable, LaSalle, Cook, 1973) partially supported the selfconcept dimensions for 125 college freshmen and indicated a need for more study of the construct validity from a larger and more heterogeneous sample.

Reliability data were based on a test-retest method using a broad sample of 626 people. Buros (1970) states the sample was sufficiently large, with varying ages, sex, race and socioeconomic status, to warrant confidence in individual difference measurements. The coefficients of correlation varied from +.60 to +.92 . Physical Self was +.87 , Personal Self was +.85 and Self Satisfaction +.88 . In 
addition, Fitts noted the striking similarity of profile patterns from repeated administration of the TSCS over long periods of time, giving further evidence of reliability (Fitts, 1965).

\section{Procedure}

The TSCS was given to both the "dance" and "no dance" groups before the beginning of the first 10 weeks session. Careful instructions were given orally. The test booklet also has the instructions, but the answer sheet on this test is confusing to some persons so the oral instructions were added to the procedure. Each set of questions on a page of the test booklet corresponds with every other row of responses on the answer sheet.

Some subjects asked about reasons for giving free dance lessons just for taking the tests. The researcher simply replied that it was part of a study. Conversation was centered as much as possible on the subject of dance and dance training. The dance group was told how the researcher's own experience in dance classes had helped her in the formulation of methods of teaching dance to middleaged women. Students were also encouraged to plan to take dance classes elsewhere after these sessions were finished.

The dance group met once a week for 10 weeks. The sessions were very much like any jazz dance class that would be given to college students except that the pacing of lessons for these older students was slower. Each exercise 
was described verbally with imagery, and the students were told what it did for the body. Learning to stand like a dancer and "finding a center" is a case in point:

Stand with the weight on the balls of your feet. You can't dance on your heels. Pull in the stomach and buttocks. Shoulders are as wide apart as they can be. They can't be pulled forward or pushed back. Head is straight on your shoulders. Pretend you have a hook in your head attached to a rope in the ceiling. You can't sag forward if something is holding you up. As you go up and down, pretend you have a greasy pole down the center of you, like a horse on a merry-go-round. Find this position, this balance, when you have to walk somewhere. Flow down the street maintaining this balance, head up, stomach in, weight on the balls of your feet, leading with your sternum. Walk down the street like a dancer.

The subjects were told not to compare their bodies to others in the class. They were told that if they joined other classes there would always be students who were better dancers. They had to learn to concentrate on their own bodies and what the instructor was saying.

The first half of each class consisted of warmup exercises (Appendix B). The instruction was interspersed with encouraging comments like the following:

Look at your own long, strong leg. Stretch it, control it. Those are the only legs you'll ever have, make them strong. Aren't they beautiful?

These supporting statements were an important part of the technique of instruction.

The second half of the session was learning steps and patterns. The steps and patterns were all done together 
with the instructor. No free movement or creative dance was used. The group was told to create at home. They were required to buy tights and leotards for the class and were told to wear them at home and to dance while they did housework. Handouts of the warm-up exercises were given out (Appendix C) and the women were told they must do the warmups every day to be prepared for class. They were told to watch dancers on television to find how many of the warmup exercises they did were incorporated into dance. It was emphasized time and again that the class was dance training. They were being trained to be dancers and were expected to continue taking classes elsewhere. A most important factor was praising the dance group for their efforts, encouraging them to go further and being careful to notice individual improvements. The classes were always conducted in a positive vein and subjects often spoke of how much they enjoyed the classes.

After the last session the tests and booklets were given out to be taken home. This was done in lieu of taking the test immediately after the last class. At the end of each class the women expressed strong feelings of exhilaration. They often commented on how good they felt and how much fun it had been. This feeling of exhilaration might have had an immediate effect on the answers if the tests had been taken right away. They were told to take the tests at their leisure and return them to the instructor within three days. 
Analysis of co-variance was used as statistical analysis. Experimental control is necessary for unbiased estimates of treatment effects (Kirk, 1968). Statistical control removes potential sources of bias when the experimenter has difficulty in complete random assignment of subjects to treatment levels. With analysis of co-variance there is statistical control by adjusting the measurement of the variate from measurement on the co-variate (Winer, 1971). 
CHAPTER V

\section{RESULTS}

An analysis of covariance was performed for each of the 10 scales of the Tennessee Self Concept Scale, with pre-test scores as covariate, post test scores as variate and dance/no dance as the independent variable. Means and standard deviations for pre and post tests and adjusted post test means are in Table $I$. The analysis of covariance is summarized in Table II.

As hypothesized, the dance group had a higher adjusted post test mean on Physical self than the no-dance group ( $F(1,26)=7.86, \mathrm{p}=.01)$. The interaction term between dance and the covariate (pre-test) is significant on the Physical Self score also ( $p .05)$. The difference in the actual slopes for predicting post-test from pre-test for the dance and no-dance groups is demonstrated in Figure I. Visual inspection indicates that the separate regression lines do not intersect until the extreme upper part of existing range of scores. Therefore, the significant interaction does not interfere with interpretation of the difference between the dance and no dance groups. There is also support for the hypothesis that the adjusted posttest mean on Personal Self would be higher for the dance group than the no-dance group $(F(1,26)=3.50, p<.05$, one tailed test). However, there was no support for the 
hypothesis that the adjusted post-test means on Self Satisfaction would be higher for the dance group $(F(1,26)=$ $.000)$.

In addition, on three other scales, the Behavior Self $(F(1,26)=8.25 \mathrm{p}<.01)$, the total $\mathrm{P}(\mathrm{F}(1,26)=$ 5.75, $\mathrm{p}<.05)$ and Identity $(\mathrm{F}(1,26)=3.38, \mathrm{p}<.10$, two tailed test, $\mathrm{p}<.05$, one tailed test) adjusted post test means for the dance group were significantly higher than for the no-dance group. The scale of Moral Ethical Self, Family Self, Social Self and Self Criticism showed no differences between the dance and no-dance adjusted post test means. (Table II).

Using the central limit Theoreom under the null hypothesis, the probability that the three of the seven unpredicted scales would show significant differences between the adjusted post test means for the dance and no-dance groups is .004 . Therefore these results can be taken as a significant finding. 
CHAPTER VI

\section{DISCUSSION}

The expectations of this study were that the TSCS scores of Physical Self, Personal Self and Self Satisfaction would show a significant increase for a group of middle-aged women volunteers who participated in a dance training program.

These expectations were met for the Physical Self and the Personal Self. The lack of change in the Self Satisfaction score was unexpected and not in keeping with the changes in the other scores. It is possible that participants in the dance training class may have set goals for themselves that they hadn't yet reached. Other unexpected results were the changes in the Behavioral Self, the Total $P$ and Identity scores.

The Behavioral self, according to fitts (1965), reflects "This is what I do or the way I act." Victor Raimy (1971), a self concept theorist, says that "self concept not only influences behavior, but is itself altered and restructured by behavior." One possible explanation for the change in the Behavioral self score may be that the participation in dance training helped to "restructure" some aspects of self esteem and then in turn, other behaviors were "influenced." 
The change in the Total $P$ score was not predicted in the original hypothesis because it seemed that while 10 weeks training might bring some change in some aspects of self concept, it would be too much to expect a significant difference in the Total $\mathrm{P}$ score.

The Identity score showed change also, indicated. higher positive gains in the dance training group. Identity, according to Fitts (1965), reflects "What the individual is."

The lack of change in Moral-Ethical Self, Family Self, Social Self and self Criticism is a strong point in support of this studies results. There is no theoretical reason for these scores to change because of participation in dance training.

Some consideration needs to be given to the idea that changes in self esteem might also occur if group lessons were given in running or calisthenics, or some other physical training. In fact, Ismail (1973) has done some work measuring personality changes with jogging. However, encouraging people to jog has its limits. Middle aged women who are a bit overweight would find jogging stressful on their skeletal systems and visceral masses. Some people find jogging distasteful and may not want to be a "jogger." Calisthenics training would provide physical improvement and group sessions could be therapeutic, but calisthenics only allow people to become "exercisers." Dance training leads to becoming a 
"dancer." Becoming a "dancer" or "learning to dance" may provide more appeal than "learning to run" or "learning to exercise."

For some people in this study, it is speculated that the appeal of the dance sessions lay in the fact that they could hope to make physical changes in themselves in a situation where they would not have to compete with younger, more agile students. The pace was geared to ability and there was a sense of "we're all in the same boat." These women might not have been able to keep up with a regular dance class. The exercises were explained more carefully than in college dance classes and the instructor could give individual attention to help the student get each movement correct.

There is also the possibility that there were some effects because of group participation. This could only be resolved by having a second no-dance group that met together as a group as regularly as the dance group took classes. The women in the dance group were often amazed at their own dancing ability. They began watching dancers on television and relating technique to movements they had learned. One woman mentioned the loss of previous back pain and two others told of trying to participate in exercise classes and finding the classes too difficult. So if group participation had some effect, it appeared to be in combination with dance. 
Some of the observed effects might also have been due to the particular technique of instruction used in this study. As noted in Chapter IV, the instructor made an effort to encourage the students by making supportive statements during their practice. The students were encouraged to think of themselves as capable, as improving and as potential dancers. The beauty and strength of their bodies were pointed out to them and they were encouraged to think of themselves in that way. This was the explicitly supportive, therapeutic aspect of the instruction which made it significantly different from the usual instruction in dance.

In conclusion, the findings in this study point to a positive relationship between participation in dance training classes and self concept, as measured by the TSCS. As stated in Chapter III, there are no previous studies relating dance training to levels of self esteem, so further research would be necessary to eliminate the possible effects of group participation or interaction with the instructor on changes in TSCS scores. This study is a start in finding a way to demonstrate, with an experimental model, that dance training may be a therapeutic tool for individuals who are reaching toward more positive feelings about the self. 
Adler, A., Practice and theory of individual psychology. Harcourt, Brace \& World, 1927.

Alperson, Erman D., Carrying experiencing forward through authentic body movement. Psychotherapy: Theory, Research \& Practice, 1974 , (Fall) 11 (32).

Bailles, Earleen, Shall we dance. Journal of Music Therapy, $1972,($ Spr) 9 (), $37-39$.

Benders, H \& Nijmegan, U. Psychiatry and objectivity: methods in the therapeutic use of movement, music \& creativity. Psychiatria, Neuroligia, Neuochirunga. $1969,72(\underline{4})$.

Best, J.F. \& Jones, J.G. Movement therapy in the treatment of autistic children. Australian Occupational Therapy Journal. 1975 (Spr), 21 (2) .

Blankenburg, $W$ \& Frieburg, $U$. Dance in the therapy of schizophrenics. Psychotherapy \& Psychosomatics. 1969, $17(\underline{5-6})$.

Buros, O.K., Ed. Personality-Test \& Review, Highland Park, N.J. Gryphon Press, 1970.

Canner, Norma. And a time to dance. 1968. Beacon Press, Boston Mass.

Coombs, A. Perceiving, behaving, becoming. Yearbook of the Assn. for supervision \& curriculum development. Wn. C.D., ASCD, 1962 .

Deiker, R. \& Lanthier, I. Construct validation of the Tennessee Self Concept Scale with emotionally disturbed adolescents. Catalog of Selected Documents in Psychology. 1975, (Summer) 5 .

Dilthey, E. Concentrated movement therapy in the context of intensified analytic group therapy. Proxis der Psychotherapie. 1971,16 (3).

Docherty, D. Education through the dance experience. Educational Design \& Consultants. Bellingham, Wn 1975 .

Dulicai, D. Movement therapy on a closed ward. Journal of the Bronx State Hospital. 1973. (Fall) 1 (任). 
Fitts, Wm. Tennessee Self Concept Scale. Counselor Recordings \& Tests. Nashville, Tennessee. 1965.

Fitts, Wm. The Self concept and performance. Studies on the self concept and rehabilitation. Social and Rehabilitation Service, Washington, D.C. 1972.

Frank, M. (ed) Selected Articles, Pittsburg Area Preschool Assn. Publication, Oct. 1975, Vol 8, No. 1-4.

Gable, R. \& La Salle, A. Cook, Keith. Dimensionality of selfperception, Tennessee self concept scale. Perceptual \& Motor Skills, 1973. Apr. Vol 36 (2) .

Garvin, B. An investigation into the relationship of personality \& physical fitness. Dissertation Abstracts International, 1972, Oct. Vol $33(\underline{4})$.

Gary, I. \& Guthrie, D. The effects of jogging on physical fitness \& self concept in hospitalized alcoholics Quarterly Journal of Studies on Alcohol, Dec. 1972 Vol 33.

Golin, S. The self esteem and goals of indigent children. Pittsburg Univ. National Institute of Health. Bethsade, Md. Nov. 1969.

Gunning, S. \& Holmes, T. Dance therapy with psychotic children: Definition \& Quantative Evaluation. Archives of General Psychology. 1973 (May) 28 (5).

Hecox, B; Levine, E. \& Scott, D. Everybody has a right to feel good: A report on the use of dance in physical rehabilitation. Rehabilitation Literature, January, 197536 (1).

Ismail, A. Young, R. The effect of chronic exercise on the personality of middle aged men by univarial and multivarial approaches. Journal of Human Ergology Sept. 1973,2 (1).

Johns, E. \& Sutton, W. Health for effective living McGraw Hill N.Y. 1954.

Kalmens, E. Low-cost individualized treatment in a day center. Hospital \& Community Psychiatry. Dec. 1970. 21 (12).

Kavaler, S. Dance therapy with retarded children. International Mental Health Research Newsletter. Spr. 197416 (1). 
Kestenberc, J. Comments on movement therapy as a psychotherapeutic tool. Journal of the American Psychoanalytic Assn. 1973, 21 (2).

Kirk, R. Experimental Design Procedure for the Behavioral Sciences Brook, Cale Publishing Co. Belmont, Calif 1968.

Langer, S., Feeling and form - a theory of art, Charles Scribner \& Sons, iJ.Y. 1953 .

Lefco, H. Dance Therapy: Narrative Case Histories of Therapy Sessions With Six Patients. Nelson-Hall, Chicago, I11., 1974 .

Levy, J. Movement therapy for psychiatric patients. American Journal of Occupational Therapy, July, 1974 , $28(6)$.

McCarthy, H. Use of the draw a person test to evaluate a dance therapy program. Journal of Music Therapy, Fall, $1973,(10)$.

McGowan, R.W. , Jarman, B., Effects of a competitive endurance training program on self concept and peer approval. Journal of Psychology $1974,52$.

Pierbot, R., Van Coppenolle, H., The measuring of movement: A methodological tool for psychosomatic research. Psychotherapy and Psychosomatics, 1973, 22.

Raimy, V., The self Concept as a Factor in Counseling and Personality Organization. Office of Educational Service, Ohio state Univ. Library, 1971.

Reed, H., Skidmore and PEP; Where the action is. Skidmore College. Program to Excite Potential 1965, is.Y.

Robinson, L., A program for deaf mental patients. Hospital and Community Psychiatry Jan. 1973,24 (1).

Rosen, E., Dance in Psychotherapy, N.Y. Bureau of Publications, Teachers College, Columbia University, 1957.

Salkin, J., Body Ego Technique: An Educational and Therapeutic Approach to Body Image and Self Identity. Charles C. Thomas, Springfield, I11., 1973.

Sandel, S., Integrating dance therapy into treatment. Hospital and Community Psychiatry. July, 197526 (7). 
Schoop, T., Mitchell, P., Won't You Join The Dance? National Press Books, Palo Alto, Calif., 1974.

Seigal, E., Movement therapy as a psychotherapeutic tool. Journal of American Psychoanalytic Assn., 1973, 21 (2).

Seriale, J., We're off To See The Wizard. Arizona State Dept. of Public Instruction. Phoenix, Ariz., 1976 .

Shaskean, D., Present trends in management of the severe emotional problems. Psychiatric Annals, Apr., 19722 (4).

Snygg, E., \& Combs, A., A New Frame of Reference For Psychology - Individual Behavior. N.Y. Harper \& Brothers Publishers, 1959.

Solnit, A., Commentary on "Movement therapy as a psychotherapeutic tool," Journal of American Psychoanalytic Assn. May 1974, 21 (2).

Vacchiano, R., Strauss, P., The construct validity of the Tennessee Self Concept Scale. Journal of Clinical Psychology 1968, 24 (3).

Weingarten, o., Mental performance during physical exertion. The benefit of being physically fit. International Journal of Sport Psychology, 1973, 4 (I).

Winer, B., Statistical Principles In Experimental Design. McGraw-Hill, N.Y. 1971.

Wylie, R., The Self Concept. University of Nebraska Press, Lincoln, Neb. 1961. The Self Concept - Revised Edition A Review of Methodological Considerations and Measuring Instruments - 1974 . 


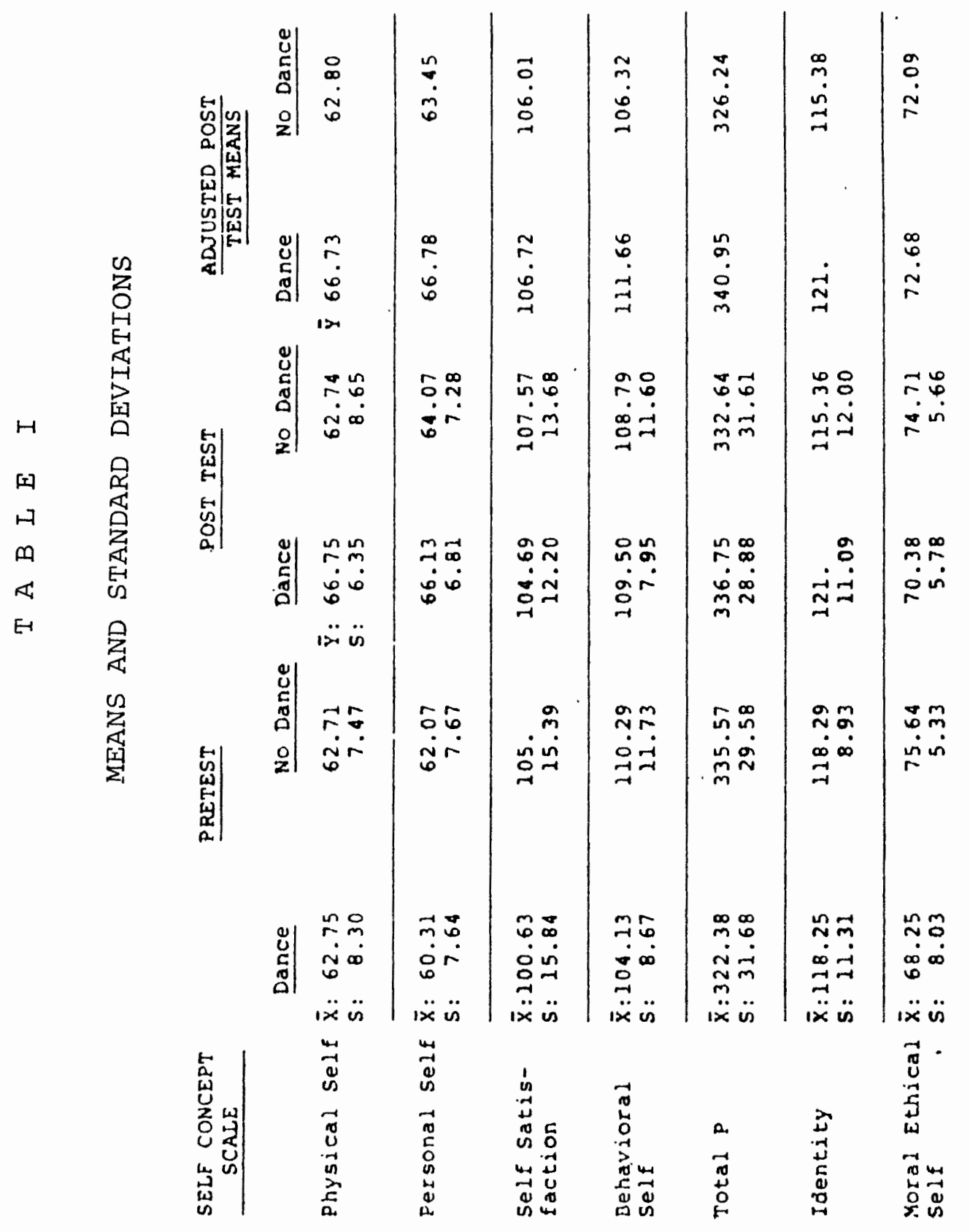




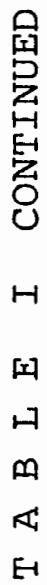

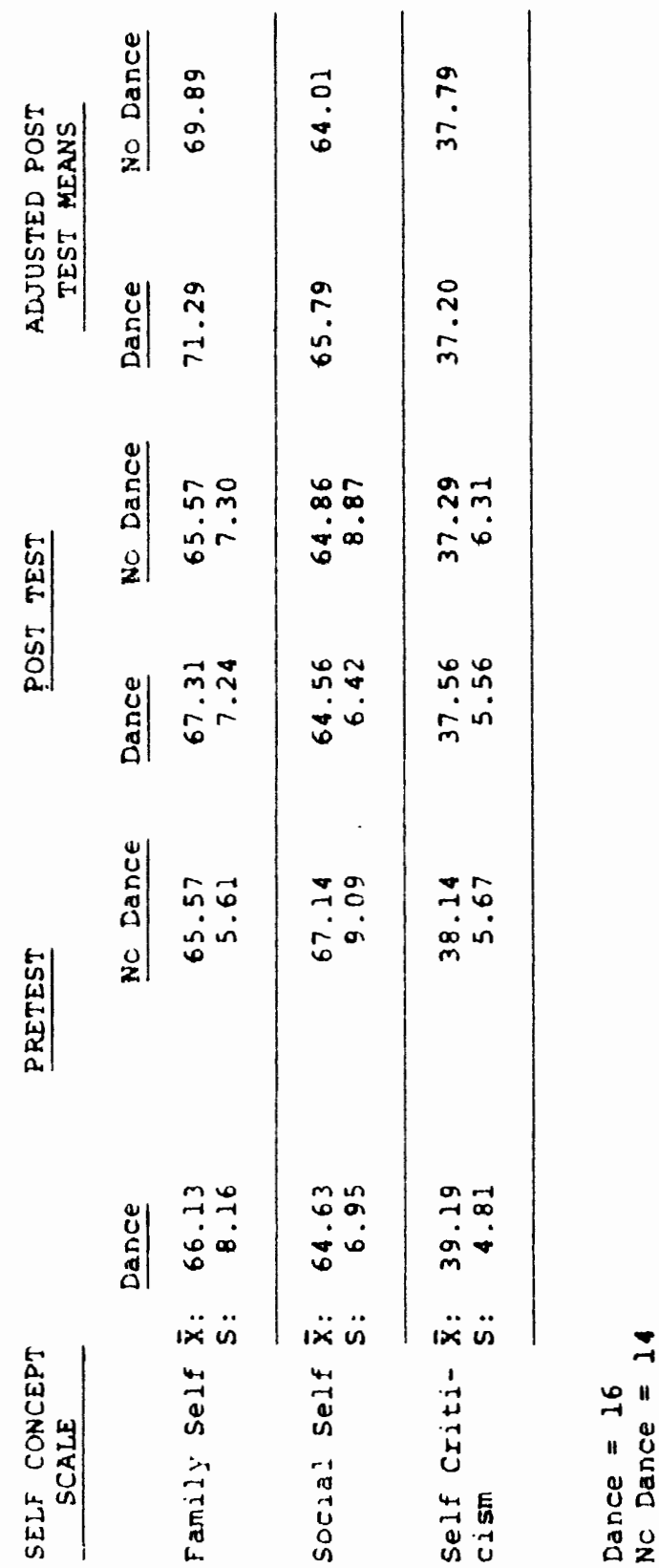




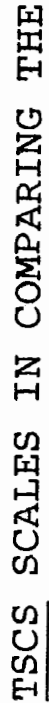

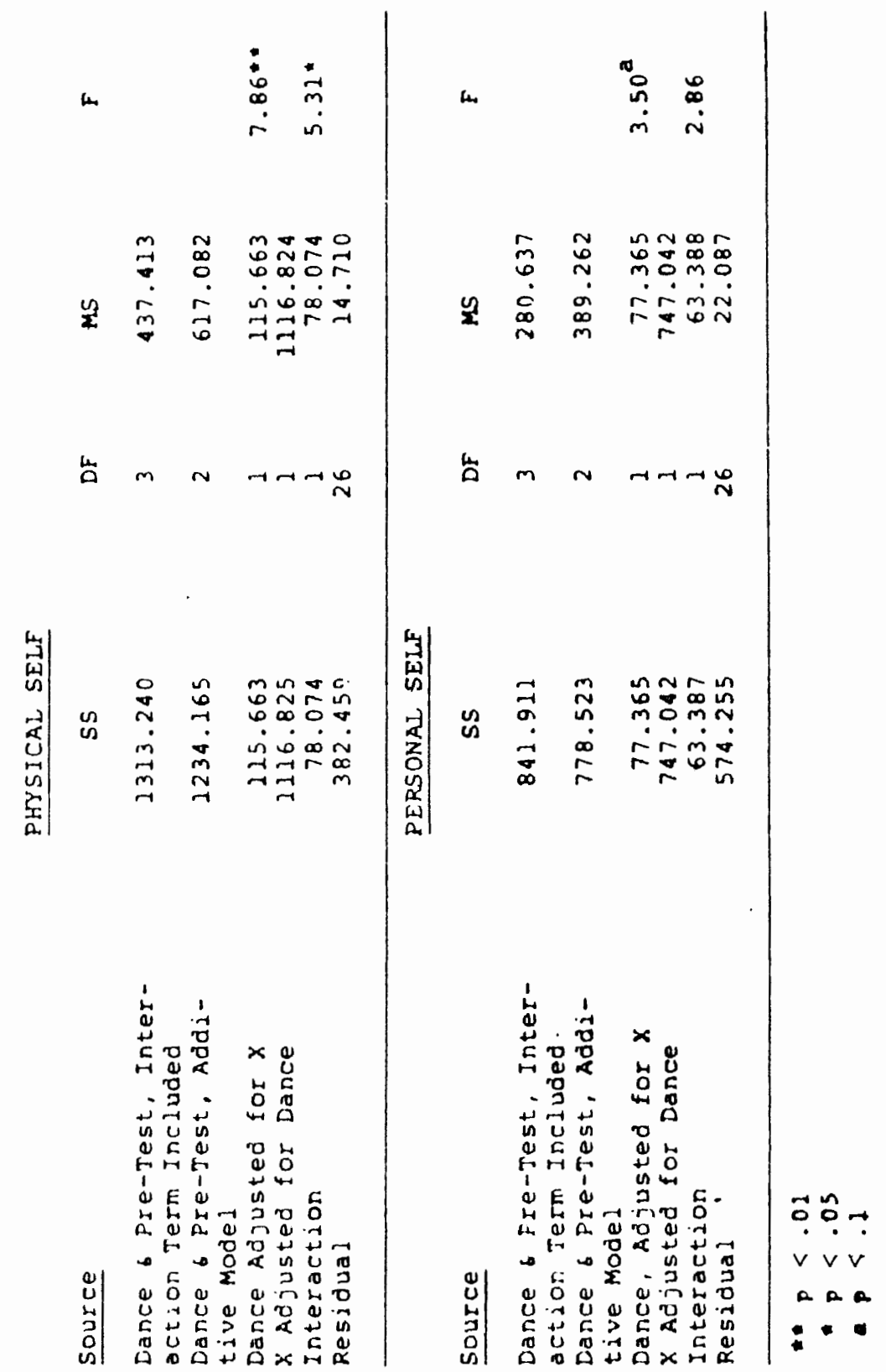









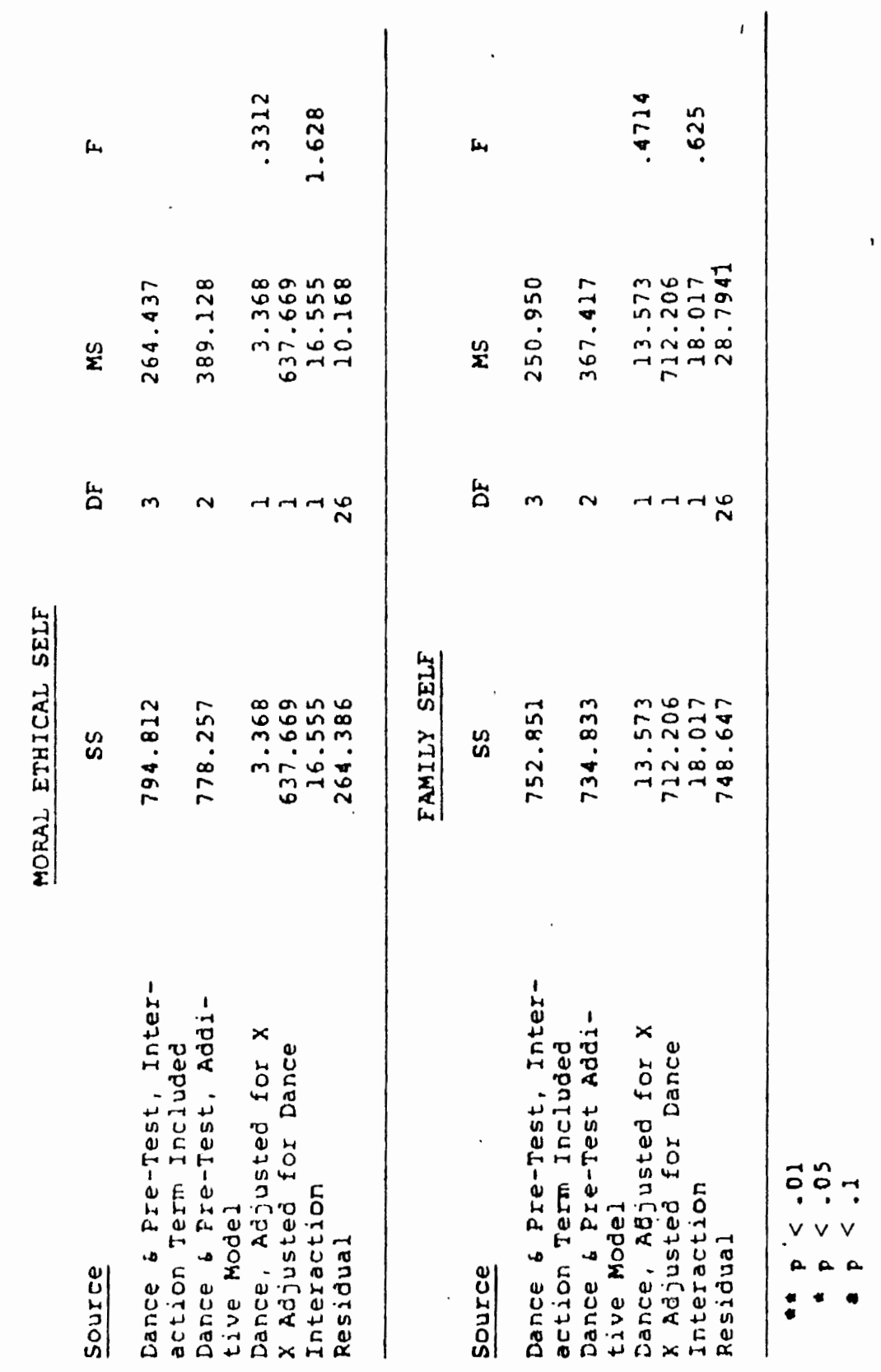




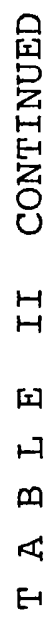

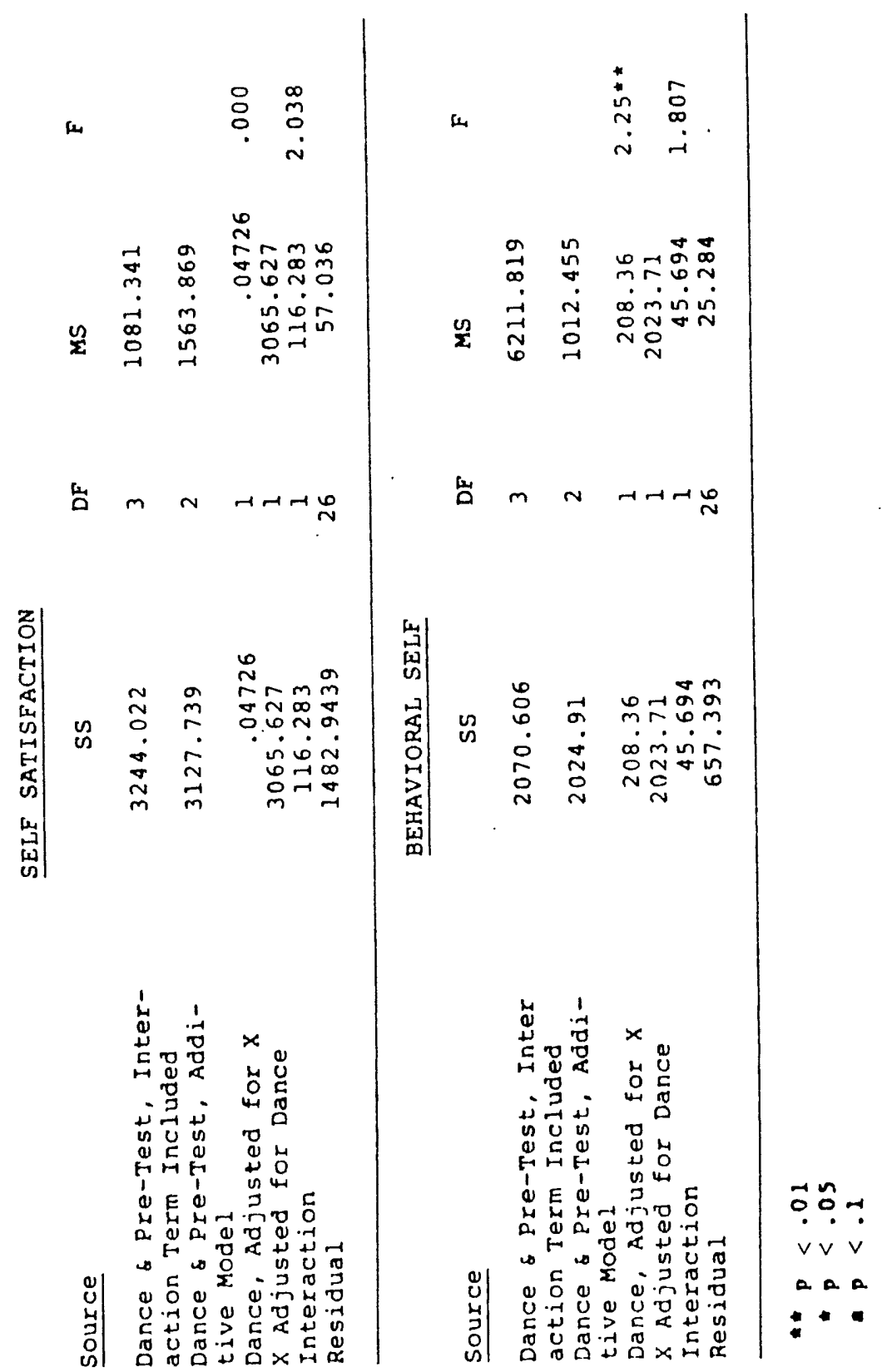


F I G U R E I

INTERACTION FOR PHYSICAL SELF SCORE

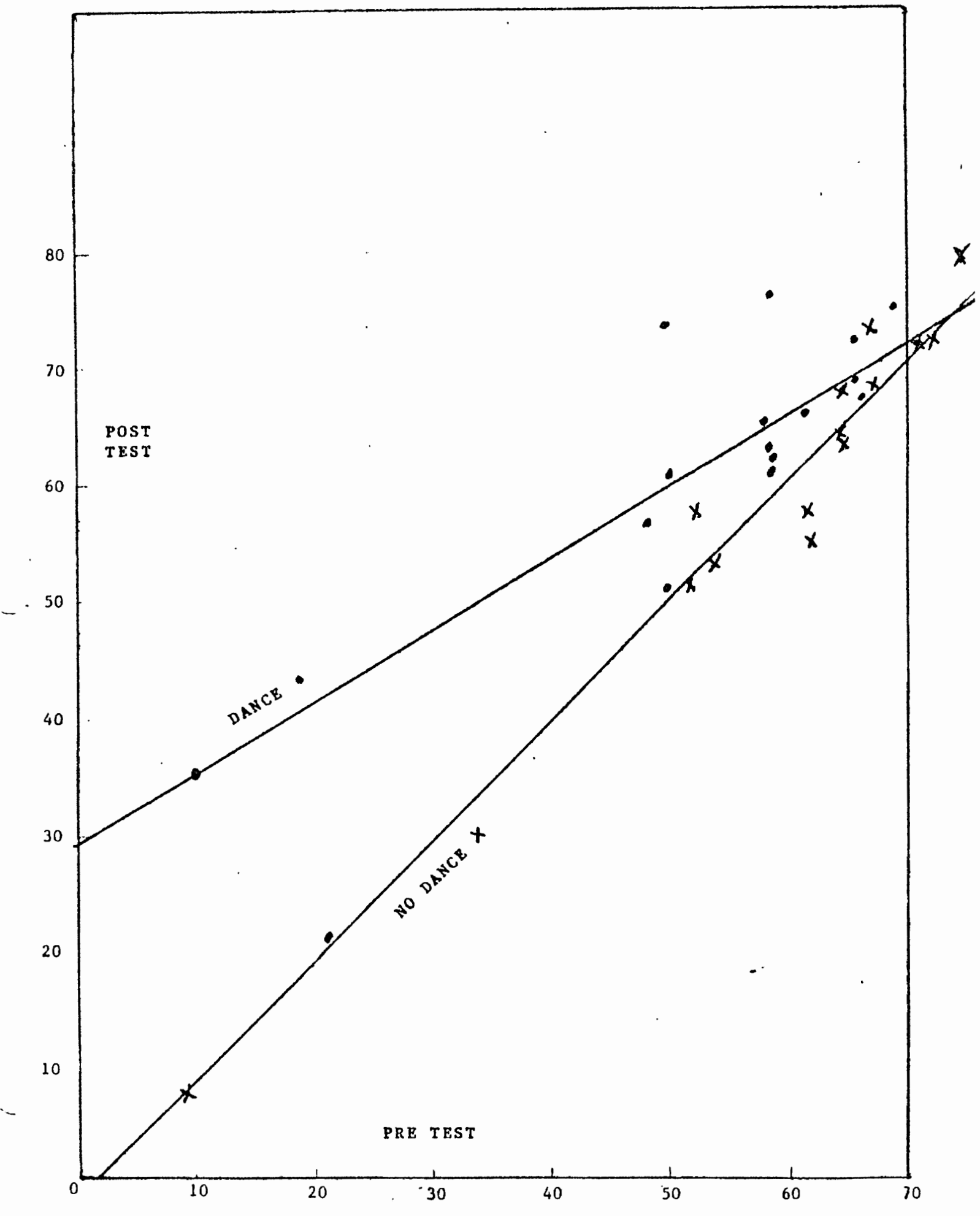


35

A $P$ P E N D I X A

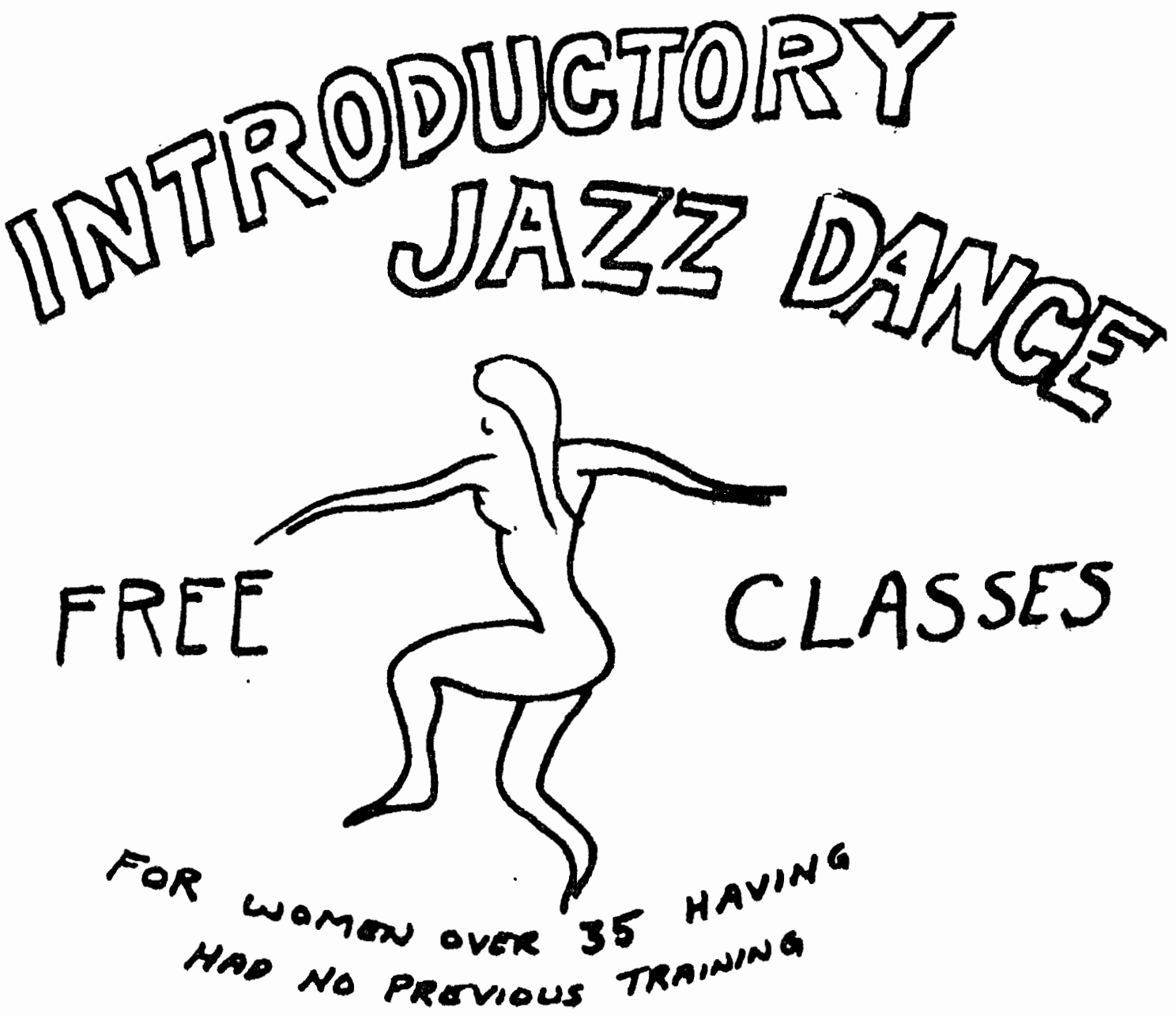

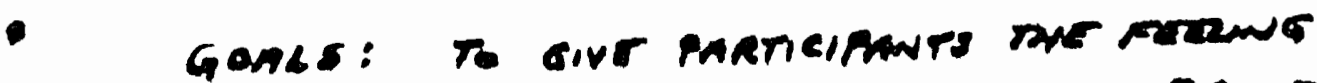

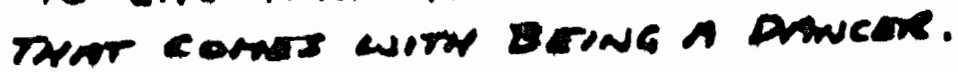

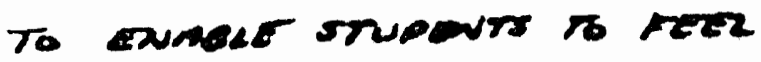
compontwate acout puesuina ruetrex DAner cunesers.

contact: Twarma Lomouist

$284-1465$

P.s.u. ofried moves $12-1$
or 3920 cramex Hall 


\section{APPENDIX B}

The first hour of the session was devoted to warm-up exercises with demonstration and verbalization of the necessity of each exercise. (All the exercises are done several times.)

1. "Stand. Sternum up. Weight on the balls of the feet. Imagine a hook on the top of your head connected to a chain. Someone pulling you up. or a merry-go-round pole down your body. You can twist around the pole or go up and down, but you can't bend over or slump." (This type of verbalization helps to find a center of balance, a way of standing and moving while dancing. It improves posture and balance. The subjects were often told to walk down the street in that manner.) "Sternum up, head on your shoulders, weight on the balls of your feet and flow down the street."

2. Maintaining the balanced position, roll the head. Drop in front, roll to one side, then the other. Then all the way around. Pretend you have ball-bearings in your neck. Roll smoothly."

3. "Isolate shoulders. Maintain standing -position, thrust one shoulder forward, then the other. Pretend your shoulders are hiitting a wall.

4. "Roll shoulders. All the way around. Reverse, all the way around." 
5. "Maintain the dance position. Thrust sternum forward - center back center. Then side - center - side center. Hips stay in place. Upper body doesn't tip, but goes side to side." (This is a difficult exercise to get started. It isolates the rib cage and is a movement not normally done.) "Rib cage forward - center - right side center - back - center - left side - center. Circle ribs, maintaining lower body steady. Front - side - back - side."

6. "Bend knees slightly, twist upper body around. Try to look at the back of room. Hold hips and knees forward." (This exercise is repeated several times, with students alternating twisting right, then left.)

7. "Maintaining balanced position, feet together, bend knees slightly. Rise on toes. Straighten knees. Stand tall. Come down. Repeat exercise with feet apart."

8. "Hands up over head. Reach with one hand toward the ceiling - then the other. Stretch the sides, under the arms. Reach - Reach - over - Flat back. Release back. Roll up."

9. "Maintain balance, with one leg slightly in back. Take that leg, swing the knee forward, back, whole leg forward, back. Knee to the diagonal, across the body, back. Then the whole leg to the diagonal, away from the body." (This is a very vigorous exercise. The subjects are to look at their own "long strong leg."). 
10. Maintain standing position. Bend legs slightly. Contract back. Release. Contract. Release.

11. "Bend knees slightly. Pelvis, front - center back - center. Side - center - front - center - side center - back - center."

12. "On the floor, sit straight - legs wide apart and point your toes hard - Push the back of your knees into the floor - Don't your legs look lovely? Those are the only legs you'll ever have - make them strong. Now flex - feet and knees - Point - Flex - Point."

13. "Maintain position - reach over to the $\mathrm{R}$ side down to the $\mathrm{R}$ leg - down to the center - down to the L leg over to the other side and up - Reverse." (This exercise gets progressively harder, becoming a turn on the floor.) 14. "Over into a plow lying on the floor, legs behind the head - Go as far as you can, legs straight - this takes practice - Have to do it every day - It stretches out the back. Roll down - one vertabra at a time - slowly - maintain control."

15. "Sit straight - legs straight out - Point hard with your long strong legs - Now flex feet back - Flex so hard your heels come off the floor - Now point - Flex - Pull your toes back - does that hurt? Good."

16. "Lie on the floor - contract your back - release contract - pretend someone's hitting.you in the stomach Release." (This exercise gets progressively harder - until 
subjects are sitting up and rolling down holding a contracted back. This takes strength.)

17. "Lie on the floor - arch the back - release-arch." (This exercise progresses until subjects arch up to the top of the head, then arch up to a sitting position, reaching down over the legs, then rolling back down.)

18. "Lie on your back - both legs straight. Pull one knee into the chest. Straighten that leg - flex straighten - lower it slowly to the floor, pointed hard, with control. Repeat with other leg."

19. "Lie on the floor. Pull one knee in - other leg stays straight. Lift knee over the body - touching the floor - buttock comes off the floor - try to keep the opposite shoulder on the floor - bring the knee back - then out to the side - both buttocks on the floor. Straighten the leg - bring it up across the body touching the floor on the other side - down around close to the floor over the other foot - out to the diagonal - straight up - lower with control down to the floor - this makes the hip more flexible repeat with other leg."

All these exercises are examples of basic jazz dance warmups. They become progressively harder and more varied. After warming up the dancers go on to practicing dance patterns and finish up dancing rather vigorously. 
1. Look to the right. Look to the left. Roll you head all the way around. (Think of your neck as having ball bearings. Keep it relaxed.)

2. Shoulders. Push one forward and then the other. (Picture yourself hitting a wall with each shoulder. Then rotate both shoulders together.

3. Isolate Ribs. $\frac{\theta}{\lambda} \frac{\theta}{\lambda} \frac{Q}{\alpha}$

4. Reach, Reach, over flat back. Release the back and hang to the floor. Roll back up.

5. Bend legs slightly. Isolate hips and pelvic area.

6. Bend legs. Go to toes. Three positions.

7. Flat on floor. Contract back into the floor. contract and sit up. $Q_{2}<O_{2}=8$

8. Arch to the top of the head. Arch up and over the legs, hold.

\section{orm Q $2<$ \&}

9. Pull knee to the chest. straighten leg. Pull toward you. Flex. Lower.

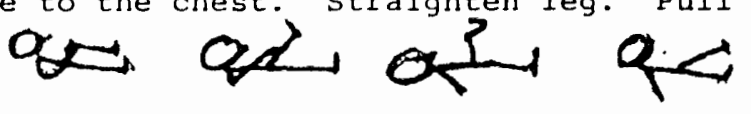

10. The plow. Relax.

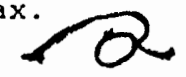

11. On the floor. Straight leg. Knee across the body. Out to the diagonal.

12. Standing. Straight leg. Knee across the body. out to the diagonal.

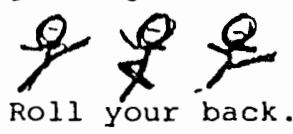

13. Straight legs. Roll your back. Bend legs. Roll your back.

14. Cobra. Raise chest off floor. Hold.

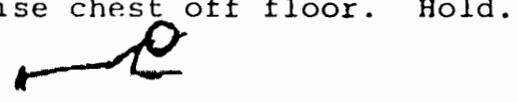

15. Sitting on floor, rotate legs, tighten buttocks.

16. Sitting on floor flex knee and ankle joints.
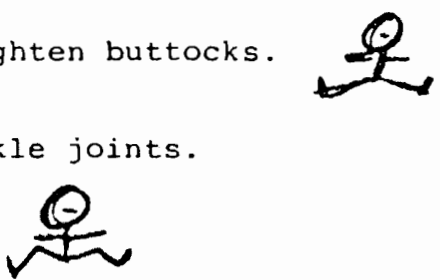